\title{
BILATERAL SYMMETRICAL SECTORAL PIGMENTARY LESION OF THE RETINA
}

\author{
BY \\ M. V. GRAHAM \\ From the Ophthalmological Department of Cardiff Royal Infirmary
}

THE condition recorded below is thought to be rare. It may well be much commoner than is generally supposed, as it is seldom incapacitating.

\section{Case Report}

A man aged 28 years was referred to me on March 7, 1962. He had recently been refracted by his optician who noted pigmentary changes in both fundi. He had worn glasses since 1952. He had never noticed any defect in his corrected vision and had not experienced any difficulty in dim light. There was no family history of eye trouble and no consanguinity in his parents. His general health had always been excellent. His parents and his only sibling (a sister) have been examined, and show normal fundi and visual fields.

Examination.-He was a normal healthy adult. The visual acuity was $6 / 5$ and N5, $-2.25 \mathrm{D}$ sph., $-1.75 \mathrm{D}$ cyl., axis $130^{\circ}$, in the right eye, and with $-2 \mathrm{D}$ sph,, $-1.5 \mathrm{D}$ cyl., axis $160^{\circ}$, in the left. Externally his eyes were normal as were both anterior segments. His fundi showed almost identical pictures (Fig. 1, opposite). The discs were normal and of good colour. The retinae and vessels were normal in both upper quadrants, but towards the periphery of both lower quadrants, the retinal vessels were markedly reduced in calibre and in these areas there was a diffuse scatter of bone corpuscle pigmentation, indistinguishable from that found in retinitis pigmentosa.

The visual fields (Fig. 2) showed an upper half defect, with a sharp edge, corresponding to the affected area of retina below. The visual fields were almost the same in dim light as in good illumination. His colour vision was normal with Ishihara diagrams.

His condition has remained absolutely unchanged during the past 9 months.

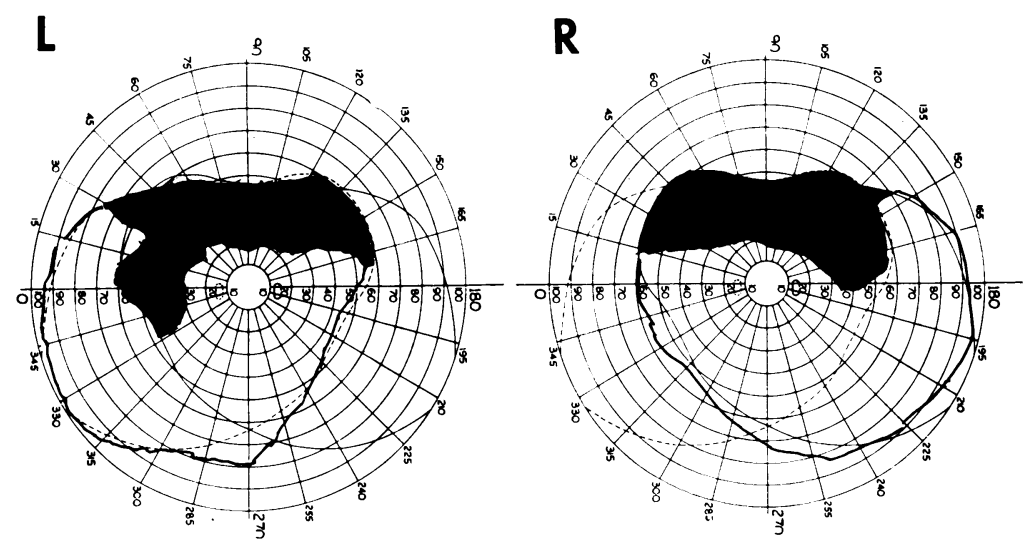

FIG. 2.-Visual fields. $1 / 330$ white object.

* Received for publication January 15, 1963. 


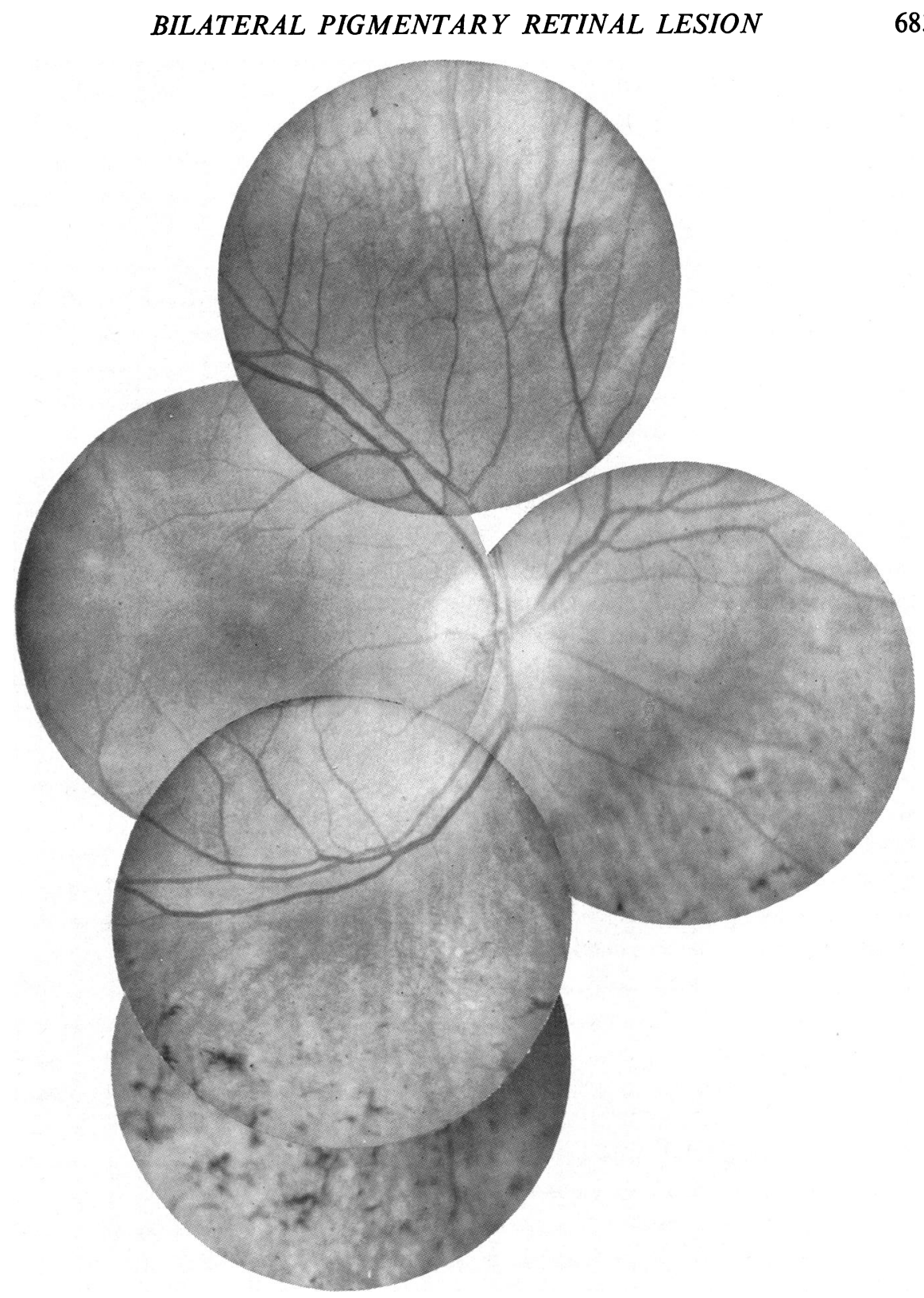

683

Fig. 1.-Appearance of fundus.

Further Investigations.- These were kindly carried out by Dr. G. B. Arden of the Institute of Ophthalmology, London.

Dark-Adaptation Curve (Fig. 3, overleaf).-The first part of this curve which corresponds to cone adaptation is normal, the second part which corresponds to rod adaptation is flatter than normal. This indicates that rod adaptation is reduced but by no means absent. As this test measures the total retinal response, the 


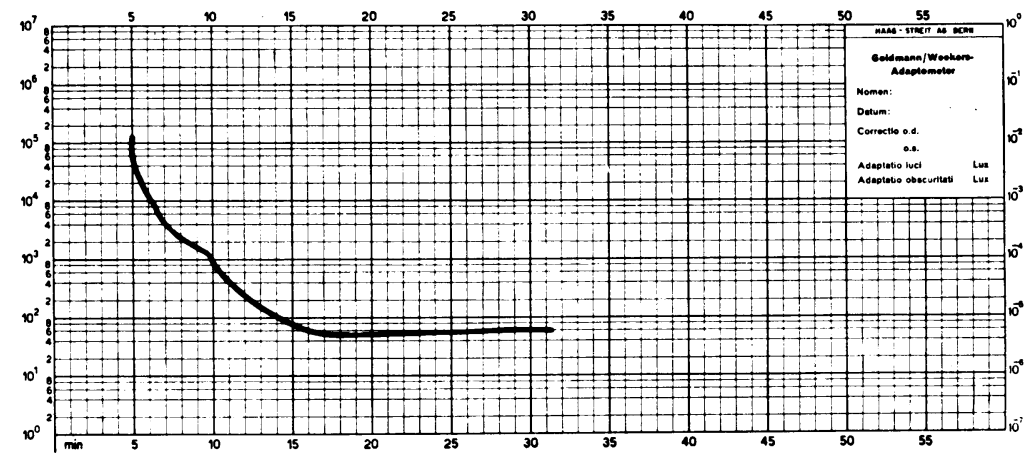

FIG. 3.-Dark-adaptation curve.

presence of a normal upper half in each retina would be sufficient to provide a reasonably good adaptation.

Electroretinogram (Fig. 4). - Two tracings, taken after $2 \mathrm{~min}$. and $10 \mathrm{~min}$. dark adaptation, show that there is virtually no increase in the amplitude of the b-wave which would normally be expected with dark adaptation. The amplitude measured $150 \mu \mathrm{V}$., compared with the normal $180-400 \mu \mathrm{V}$., showing that rod function although present is diminished. Here, as with dark adaptation, it is impossible to examine selected areas of the retina and the response recorded represents the sum total of the response of the whole retina.
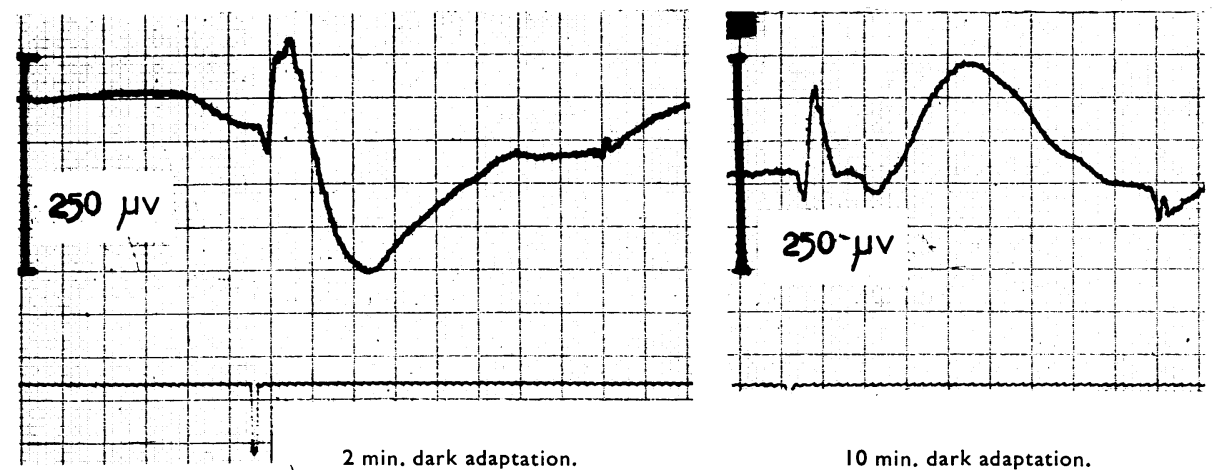

FIG. 4.-Electroretinogram after $2 \mathrm{~min}$. and $10 \mathrm{~min}$. dark adaptation.

Electro-oculogram (Fig. 5, opposite).-The curves are similar for each eye. They show a definite light rise. The ratio, light peak/dark trough $=130$ per cent. (normal approx. 200 per cent.). The potential generator in this test is the pigment epithelium.

Comment.-The subnormal results in these tests suggest some loss of rod function, probably secondary to a lesion in the affected area of pigment epithelium. However, the normal retina outside the clinically affected area is sufficient to produce enough potential for curves approaching, but not reaching, normal values.

A bilateral symmetrical sectoral pigmentary lesion of the retina was diagnosed. 


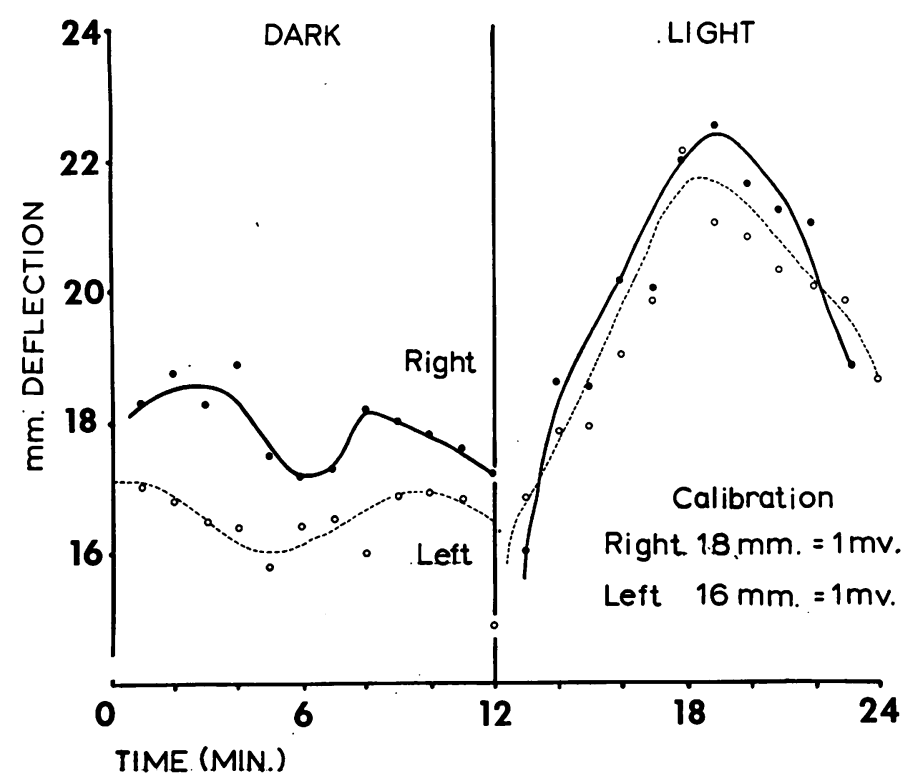

FIG. 5.-Electro-oculogram. Ratio light peak/dark trough $=130$ per cent.

\section{Discussion}

Relatively few cases of sector-shaped pigmentary retinal lesions have been reported in the literature. Five cases in one family were recorded by Küper (1960) and three in one family by Hommer (1959). Further cases in two families with confirmed heredity were recorded by Lisch (1955). Sporadic cases have been recorded by several authors (Bietti, 1937; Verrey, 1947; Tavolara, 1949; Rubino, 1949).

It is important to distinguish this condition from classical retinitis pigmentosa.

The disease is limited to the lower retinal quadrants only. There may sometimes be relative sparing of the lower temporal quadrant. Characteristically it is said to be non-progressive, with only a slight disturbance of dark adaptation and with good visual acuity. The field defects correspond with the affected retinal quadrants. Only in these quadrants is there any vascular attenuation; elsewhere, unlike retinitis pigmentosa of the classical type, the vessel calibre is quite normal. These cases are further distinguished from classical retinitis pigmentosa by having a measurable electroretinogram and electro-oculogram, though these are often slightly diminished in amplitude.

Prognosis.-If progression does take place it is said to be slow and no cases have been recorded in which the upper retinal quadrants were subsequently 
affected. However, the prognosis as yet must be somewhat guarded, as most of these cases have not had sufficiently long terms of observation.

Because of the site of the field defect and the minimal disturbance of dark adaptation, these patients are often diagnosed only by accident, for example on routine refraction. It may well be, therefore, that the condition is frequently overlooked.

\section{Summary}

A case of bilateral symmetrical sectoral pigmentary lesion of the retina is described and its differentiation from classical retinitis pigmentosa is discussed.

Because of the absence of disabling symptoms, it is suggested that this condition may be commoner than would be supposed from the meagre reports in the literature.

About 50 per cent. of the reported cases have had a hereditary basis.

It is probably non-progressive or very slowly progressive.

My thanks are due to Prof. Arnold Sorsby for his generous advice and encouragement and to Dr. G. B. Arden, for his assistance with the special investigations.

\section{REFERENCES}

BIETTI, G. (1937). Boll. Oculist., 16, 1159.

HOMMER, K. (1959). v. Graefes Arch. Ophthal., 161, 16.

KÜPER, J. (1960). Klin. Mbl. Augenheilk., 136, 97.

LISCH, K. (1955). Forschung u. Praxis, 10, 54.

RuBINo, A. (1949). G. ital. Oftal., $2,417$.

Streiff, E. B., and Hermann, C. (1950). Bull. Soc. franc. ophtal., 63, 300.

TAVOlARA, L. (1949). G. ital. Oftal, $2,52$.

VERREY, F. (1947). Ophthalmologica (Basel), 114, 278. 